\title{
Spinal anesthesia instead of general anesthesia for infants undergoing tendon Achilles lengthening
}

This article was published in the following Dove Press journal:

Local and Regional Anesthesia

\author{
Mohammad AISuhebani' \\ David P Martin ${ }^{1,2}$ \\ Lance M Relland ${ }^{1,2}$ \\ Tarun Bhalla ${ }^{1,2}$ \\ Allan C Beebe ${ }^{3}$ \\ Amanda T Whitaker ${ }^{3}$ \\ Walter Samora ${ }^{3}$ \\ Joseph D Tobias ${ }^{1,2}$ \\ 'Department of Anesthesiology \& \\ Pain Medicine, Nationwide Children's \\ Hospital, Columbus, OH, USA; \\ ${ }^{2}$ Department of Anesthesiology \& \\ Pain Medicine, The Ohio State \\ University College of Medicine, \\ Columbus, OH, USA; ${ }^{3}$ Department \\ of Orthopedic Surgery, Nationwide \\ Children's Hospital and The Ohio \\ State University College of Medicine, \\ Columbus, $\mathrm{OH}$, USA
}

Correspondence: Mohammad AISuhebani Department of Anesthesiology \& Pain Medicine, Nationwide Children's Hospital, 700 Children's Drive

Columbus, $\mathrm{OH} 43205$, USA

$\mathrm{Tel}+\mathrm{I} 6147224200$

Fax +I 6147224203

Email Alsuhebani.Mohammad@

Nationwidechildrens.org

\begin{abstract}
Spinal anesthesia (SA) has been used relatively sparingly in the pediatric population, as it is typically reserved for patients in whom the perceived risk of general anesthesia is high due to comorbid conditions. Recently, concern has been expressed regarding the potential long-term neurocognitive effects of general anesthesia during the early stages of life. In view of this, our center has developed a program in which SA may be used as the sole agent for applicable surgical procedures. While this approach in children is commonly used for urologic or abdominal surgical procedures, there have been a limited number of reports of its use for orthopedic procedures in this population. We present the use of SA for 6 infants undergoing tendon Achilles lengthening, review the use of SA in orthopedic surgery, describe our protocols and dosing regimens, and discuss the potential adverse effects related to this technique.
\end{abstract}

Keywords: spinal anesthesia, orthopedic surgery, tendon Achilles lengthening

\section{Introduction}

Tendon Achilles lengthening (TAL) is a brief surgical procedure during which the Achilles tendon is lengthened in the treatment of congenital orthopedic deformities of the foot. ${ }^{1}$ The procedure involves a skin incision and a tenotomy that can be performed under general anesthesia in the operating room or under local anesthesia in the office or a procedure room. The choice of location and anesthetic technique may be influenced by associated comorbid conditions, parental concerns, or surgeon's preference. While the exposure to general anesthesia is brief, there have been recent concerns based on laboratory and animal studies that exposure to certain anesthetic agents may affect long-term neurocognitive outcome. ${ }^{2-5}$ In response to such concerns from both surgeons and parents, our institution has developed a program in which spinal anesthesia (SA) is used in lieu of general anesthesia for brief surgical procedures. ${ }^{6}$ We report the use of SA instead of general anesthesia in a cohort of 6 infants undergoing TAL. We present the use of SA for 6 infants undergoing TAL, review the use of SA in orthopedic surgery, describe our protocols and dosing regimens, and discuss the potential adverse effects related to this technique.

\section{Methods}

The retrospective review and presentation of these cases was approved by the Institutional Review Board of Nationwide Children's Hospital (IRB17-00643). Per their routine practice and policy for retrospective chart reviews, the Institutional Review 
Board did not require informed parental consent. The study data were stored and handled securely to protect patient confidentiality. The charts were reviewed for patient demographics (chronological and gestational age, weight, and associated comorbid conditions). Anesthetic information included the medications used for SA, duration of the procedures, and problems with placement of SA. Adverse effects related to SA, including hypotension, bradycardia, or respiratory insufficiency, were noted. The efficacy of the block was determined by noting the response to the surgical incision and the ability to complete the procedure without supplemental anesthetic agents. The intraoperative need for sedative agents was recorded. The postoperative disposition was noted, including the need for inpatient admission.

\section{Results}

The specifics of the technique for spinal anesthetic care were similar for all cases. On the day of surgery, the patient was held nil per os for 2 hours for clear liquids. After discussion with the parents and review of the anesthetic options, informed consent was obtained for SA. Preoperatively, a topical anesthetic cream was applied midline over the lumbar region of the spine. After transferring the patient to the operating room, applying standard American Society of Anesthesiologists monitors, and cleansing the lumbar area with chlorhexidine, SA was performed using aseptic technique while the patient was awake and positioned in the sitting position. A 22 gauge, 1.5-inch spinal needle with stylet was inserted at the L3-L4 interspace and advanced carefully until free flow of cerebrospinal fluid was obtained. At that time, 1 $\mathrm{mL}$ of isobaric $0.5 \%$ bupivacaine $(5 \mathrm{mg})$, with epinephrine $1: 200,000$ and containing $5 \mu \mathrm{g}$ of clonidine, was injected. The infant was then placed supine. Motor and sensory blocks were achieved within 60 seconds.
The study cohort included 6 infants undergoing TAL surgery. The specific demographic data and information regarding the SA are outlined in Table 1. No changes in vital signs were noted following the onset of SA or during the procedure. No supplemental analgesic medications or sedation was provided during the procedures. No response to the surgical incision was noted in any patient. All of the patients were transferred to the postoperative anesthesia care unit for recovery and then discharged home with no need for postoperative analgesia during the immediate recovery period.

\section{Discussion}

The clinical use of SA in infants was first reported in the early 20 th century when the potential for morbidity and mortality from general anesthesia was significant. ${ }^{7}$ SA saw a resurgence during the 1980s as a means of avoiding general anesthesia and endotracheal intubation in former preterm infants with underlying pulmonary pathology, such as bronchopulmonary dysplasia, or to avoid apnea and respiratory insufficiency following general anesthesia with halothane. ${ }^{8,9}$ However, enthusiasm decreased with the introduction of newer inhalational anesthesia agents (sevoflurane and desflurane), which were shown to have a lower risk of postoperative apnea. ${ }^{10,11}$ Recently, the interest in SA has been renewed given the theoretical concerns raised by laboratory and animal studies suggesting that exposure to certain anesthetic agents may have negative long-term cognitive effects.

Over the years, SA has been used with great success for various surgical procedures below the umbilicus, most commonly inguinal herniorrhaphy. ${ }^{12}$ However, the technique can be used for many procedures, including lower extremity orthopedic procedures, as demonstrated by our case series of 6 infants undergoing TAL. To date, there are limited reports

Table I Demographic and intraoperative data

\begin{tabular}{|c|c|c|c|}
\hline $\begin{array}{l}\text { Patient } \\
\text { no. }\end{array}$ & Demographic data & Spinal dosing regimen & Operating room time \\
\hline 1 & 2-month-old, $6.7 \mathrm{~kg}$ infant, term birth, healthy & $\begin{array}{l}\mathrm{I} \mathrm{mL} \text { of isobaric } 0.5 \% \text { bupivacaine with epinephrine } \\
\mathrm{I}: 200,000 \text { and } 5 \mu \mathrm{g} \text { of clonidine }\end{array}$ & 30 minutes \\
\hline 2 & 2-month-old, $6.2 \mathrm{~kg}$ infant, term birth, healthy & $\begin{array}{l}\mathrm{I} \mathrm{mL} \text { of isobaric } 0.5 \% \text { bupivacaine with epinephrine } \\
\mathrm{I}: 200,000 \text { and } 5 \mu \mathrm{g} \text { of clonidine }\end{array}$ & 30 minutes \\
\hline 3 & $\begin{array}{l}\text { 2-month-old, } 4.75 \mathrm{~kg} \text { infant with history of preterm } \\
\text { birth at } 31 \text { weeks of gestation with a history of } \\
\text { pulmonary hypertension }\end{array}$ & $\begin{array}{l}0.9 \mathrm{~mL} \text { of isobaric } 0.5 \% \text { bupivacaine with epinephrine } \\
\mathrm{I}: 200,000 \text { and } 5 \mu \mathrm{g} \text { of clonidine }\end{array}$ & 35 minutes \\
\hline 4 & 2-month-old, $6.2 \mathrm{~kg}$ infant, term birth, healthy & $\begin{array}{l}\mathrm{I} \mathrm{mL} \text { of isobaric } 0.5 \% \text { bupivacaine with epinephrine } \\
\mathrm{I}: 200,000 \text { and } 5 \mu \mathrm{g} \text { of clonidine }\end{array}$ & 35 minutes \\
\hline 5 & I0-week-old, $5.8 \mathrm{~kg}$ infant, term birth, healthy & $\begin{array}{l}\mathrm{I} \mathrm{mL} \text { of isobaric } 0.5 \% \text { bupivacaine with epinephrine } \\
\mathrm{I}: 200,000\end{array}$ & 30 minutes \\
\hline 6 & 7-week-old, $6.1 \mathrm{~kg}$ infant, term birth, healthy & $\begin{array}{l}\text { I } \mathrm{mL} \text { of isobaric } 0.5 \% \text { bupivacaine with epinephrine } \\
\mathrm{I}: 200,000\end{array}$ & 30 minutes \\
\hline
\end{tabular}


of the use of SA for lower extremity orthopedic procedures in infants and children (Table 2). ${ }^{13-18}$ These reports, along with our current anecdotal experience, demonstrate the feasibility, efficacy, and safety of the technique for lower extremity orthopedic procedures.

Over the years, various techniques and dosing regimens have been reported for SA in infants and children. ${ }^{12,19-21} \mathrm{We}$ have recently reported our experience, technique, and current dosing regimen, which have been established for our SA program in infants and children. ${ }^{6}$ Patients are considered to be potential candidates for SA if they require lower abdominal, urological, or lower orthopedic surgery with a duration of $\leq 90$ minutes. Although we initially limited the use of SA to children less than 6 months of age, as our experience has increased, we have included older children. Some patients undergoing SA may not require an intravenous catheter prior to placement of the SA. For brief procedures such as TAL, given the safety profile of SA and our significant experience with the technique, we may choose to place SA and complete the procedure without securing intravenous access. However, although the hemodynamic changes are minimal in infants and complications such as total SA rare, a failure of the technique or an unexpected prolongation of surgery can occur, and consideration should be given to placing intravenous access in most patients. Topical local anesthetic cream $\left(\mathrm{LMX}^{\circledR} 4 \%\right.$ lidocaine cream, Ferndale Laboratories, Ferndale, MI, USA) is applied to the area over the lumbar spine $\sim 30-45$ minutes prior to the procedure. The patients are held nil per os per our usual operating room routine. As tolerated by the patients, routine American Society of Anesthesiologists monitors are placed before administration of the spinal anesthetic. The procedure is performed under sterile conditions with the child in the sitting position and gently restrained. We use a pre-prepared, sterile SA kit that was manufactured specifically for infant and child SA (Cardinal Health, Dublin, OH, USA). The kit contains sterile preparation solution, a fenestrated drape, and syringes that are used to draw up medications required for SA. The intrathecal space is accessed using either a 1.5-inch, 22-gauge or 1-inch, 25-gauge spinal need with stylet (Becton Dickinson, Franklin Lakes, NJ, USA), depending on the anesthesiologist's preference and the size of the patient. Access to the intrathecal space is confirmed when return of cerebrospinal fluid is achieved. Although using only the local anesthetic agent (bupivacaine) provides successful SA in infants and children, we use a combination of medications designed to maximize the duration of the SA and postoperative analgesia. This includes preservative-free isobaric bupivacaine $(0.5 \%)$ at a dose of $0.2 \mathrm{~mL} / \mathrm{kg}(1 \mathrm{mg} / \mathrm{kg})$ with epinephrine (1:200,000 or $5 \mu \mathrm{g} / \mathrm{mL})$ and clonidine $(1 \mu \mathrm{g} / \mathrm{kg})$ to prolong the duration of surgical anesthesia. ${ }^{22}$ We generally recommend a maximum dose of $1 \mathrm{~mL}$ ( $5 \mathrm{mg}$ ) for most patients; however, for longer procedures or larger children, a higher total volume can be used $(1.2 \mathrm{~mL}$ or $6 \mathrm{mg})$. Following the block, the patient is

Table 2 Previous reports regarding the use of SA for orthopedic procedures in infants and children

\begin{tabular}{|c|c|c|}
\hline Authors and reference & Study cohort & Outcomes \\
\hline Tobias $^{13}$ & $\begin{array}{l}\text { 8-year-old, } 28 \mathrm{~kg} \text { boy with Morquio syndrome } \\
\text { for bilateral femoral osteotomies. Potential } \\
\text { difficult airway on preoperative examination. }\end{array}$ & $\begin{array}{l}\text { Continuous SA with a } 20 \text {-gauge catheter placed through an } 18 \text { gauge } \\
\text { Tuohy needle at the L3-L4 interspace. Hyperbaric }(0.75 \% \text { in } 10 \% \\
\text { dextrose) bupivacaine dosed incremental starting with } 0.3 \mathrm{mg} / \mathrm{kg} \text { for } \\
\text { the } 2 \text { hours } 15 \text { minutes procedure. }\end{array}$ \\
\hline Tobias and Mencio ${ }^{14}$ & $\begin{array}{l}\text { SA for unilateral clubfoot repair in } 5 \text { children. } \\
\text { Four in a developing country and one with } \\
\text { history of malignant hyperthermia. }\end{array}$ & $\begin{array}{l}\text { SA with } 0.75 \% \text { hyperbaric bupivacaine }(0.5-0.6 \mathrm{mg} / \mathrm{kg}) \text { with } \\
\text { epinephrine. }\end{array}$ \\
\hline Aronsson et $\mathrm{al}^{15}$ & $\begin{array}{l}\text { Twenty-two infants (average age: II weeks with } \\
\text { a range of I day-10 months) undergoing } 23 \\
\text { surgical procedures of the spine, hip, or lower } \\
\text { extremities. }\end{array}$ & $\begin{array}{l}\text { SA with } 1 \% \text { hyperbaric tetracaine }(0.5 \mathrm{mg} / \mathrm{kg}) \text {. Surgical procedures } \\
\text { included closure of meningomyelocele, adductor tenotomy, club } \\
\text { foot repair, incision and drainage, muscle biopsy, and tendon Achilles } \\
\text { lengthening. }\end{array}$ \\
\hline Abajian et al $^{16}$ & $\begin{array}{l}\text { Single-center cohort of } 78 \text { infants undergoing } \\
\text { various surgical procedures. }\end{array}$ & $\begin{array}{l}\text { SA with I\% hyperbaric tetracaine }(0.2-0.32 \mathrm{mg} / \mathrm{kg}) \text {. Surgical } \\
\text { procedures included incision and drainage of a septic hip, amputation } \\
\text { of a foot, bilateral adductor myotomy and tenotomy, closed } \\
\text { reduction of dislocated hips with cast application, and club foot } \\
\text { repair. }\end{array}$ \\
\hline Puncuh et al ${ }^{17}$ & $\begin{array}{l}\text { Large single-center experience of SA including } \\
327 \text { infants and children undergoing lower } \\
\text { extremity procedures. }\end{array}$ & $\begin{array}{l}\text { SA with } 0.5 \% \text { hyperbaric bupivacaine }(0.2 \mathrm{mg} / \mathrm{kg}) \text { in a large cohort of } \\
\text { pediatric patients including } 327 \text { patients undergoing lower extremity } \\
\text { surgery. }\end{array}$ \\
\hline Bang-Vojdanovski ${ }^{18}$ & $\begin{array}{l}\text { Large single-center experience with SA for } \\
\text { orthopedic procedures }\end{array}$ & $\begin{array}{l}\text { SA with } 0.5 \% \text { hyperbaric bupivacaine }(0.5-1 \mathrm{mg} / \mathrm{kg}) \text {. Hypotension } \\
\text { noted in patients } \geq 5 \text { years of age. }\end{array}$ \\
\hline
\end{tabular}

Abbreviation: SA, spinal anesthesia. 
placed in the supine position, taking care to not elevate the pelvis, as this may result in cephalad spread of the level of SA. Monitors are applied with the blood pressure cuff on the lower extremity if feasible. Most children exhibit a dense sensory and motor blockade, but we occasionally place a piece of tape across the distal thighs to minimize leg movement that may compromise operating conditions. The child is then prepped and draped as per routine, and the surgical procedure performed. As a result of the decreased sensory input to the central nervous system caused by SA, many children will fall asleep on their own shortly after the block takes effect. If the child is fussy, a pacifier dipped in SweetEase $^{\circledR}$ (sucrose $24 \%$ ) can be used to provide distraction for the patient. In cases when soothing measures fail, small doses of intravenous sedatives such as midazolam or an infusion of dexmedetomidine can be administered.

Adverse effects related to SA are generally rare, especially in the pediatric population. Relative contraindications include uncorrected coagulopathy, localized infection at the insertion site, anatomical malformations of the spinal cord/vertebral column, and intracranial hypertension. Given the later development of the sympathetic nervous system, hypotension is rare and in fact, blood pressure stability has been shown to be better with SA than general anesthesia. ${ }^{23}$ High spinal blockade due to excessive dosing or improper positioning may result in respiratory compromise, apnea, and hemodynamic effects. ${ }^{24,25}$ Therefore, standard American Society of Anesthesiologists intraoperative monitoring is mandatory. Postdural puncture headache remains uncommon in pediatric patients less than 10-12 years of age, while other rare neurological complications, including subdural hematoma, generally occur in the setting of comorbid defects of coagulation function. Postoperatively, infants and children who do not require sedation can be considered candidates to bypass the postoperative anesthesia care unit and proceed directly to Phase II or step-down care, unless the child requires hospital admission for other reasons. While the risk of apnea is decreased with spinal versus general anesthesia, postoperative monitoring for 6-8 hours is recommended for the former preterm infant who is $<60$ weeks post-gestational age. ${ }^{26}$

The use of regional anesthesia techniques should be considered as an effective and safe alternative to avoid the potential adverse effect of general anesthesia, especially in patients with comorbid conditions. SA may avoid concerns regarding airway manipulation, respiratory effects, neurocognitive effects, and postoperative apnea following general anesthesia. In our cohort of patients, SA provided effective anesthesia during TAL surgery without hemodynamic or respiratory compromise. None of the patients required sedation during or after SA. These case reports, the current literature, and our clinical experience suggest that SA may offer clinical benefits over general anesthesia for lower extremity orthopedic procedures in infants.

\section{Disclosure}

The authors report no conflicts of interest in this work.

\section{References}

1. MacNeille R, Hennrikus W, Stapinski B, Leonard G. A mini-open technique for Achilles tenotomy in infants with clubfoot. J Child Orthop. 2016;10:19-23.

2. Jevtovic-Todorovic V, Hartman RE, Izumi Y, et al. Early exposure to common anesthetic agents causes widespread neurodegeneration in the developing rat brain and persistent learning deficits. $J$ Neurosci. 2003;23:876-82.

3. Coleman K, Robertson ND, Dissen GA, et al. Isoflurane anesthesia has long-term consequences on motor and behavioral development in infant rhesus macaques. Anesthesiology. 2017;126:74-84.

4. Davidson AJ, Disma N, de Graaff JC, et al. Neurodevelopmental outcome at 2 years of age after general anaesthesia and awake-regional anaesthesia in infancy (GAS): an international multicentre, randomised controlled trial. Lancet. 2016;387:239-250.

5. Sun LS, Li G, Miller TL, et al. Association between a single general anesthesia exposure before age 36 months and neurocognitive outcomes in later childhood. JAMA. 2016;315:2312-2320.

6. Whitaker EE, Wiemann BZ, DaJusta DG, et al. Spinal anesthesia for pediatric urological surgery: reducing the theoretic neurotoxic effects of general anesthesia. J Pediatr Urol. 2017;13:396-400.

7. Bainbridge W. A report of twelve operations on infants and young children during spinal anesthesia. Arch Pediatr. 1901;18:570-574.

8. Welborn LG, Hannallah RS, Luban NL, Fink R, Ruttimann UE. Anemia and postoperative apnea in former preterm infants. Anesthesiology. 1991;74:1003-1006.

9. Krane EJ, Haberkern CM, Jacobson LE. Postoperative apnea, bradycardia, and oxygen desaturation in formerly premature infants: prospective comparison of spinal and general anesthesia. Anesth Analg. 1995;80:7-13.

10. William JM, Stoddart PA, Williams SA, Wolf AR. Post-operative recovery after inguinal herniotomy in ex-premature infants: comparison between sevoflurane and spinal anaesthesia. Br J Anaesth. 2001;86:366-371.

11. Sale SM, Read JA, Stoddart PA, Wolf AR. Prospective comparison of sevoflurane and desflurane in formerly premature infants undergoing inguinal herniotomy. Br J Anaesth. 2006;96:774-778.

12. Tobias JD. Spinal anesthesia in infants and children. Paediatr Anaesth. 2000;10:5-16.

13. Tobias JD. Anesthetic care for the child with Morquio syndrome: general versus regional anesthesia. J Clin Anesth. 1999;11:242-246.

14. Tobias JD, Mencio GA. Regional anesthesia for club foot surgery in children. Amer J Ther. 1998;5:273-277.

15. Aronsson DD, Gemery JM, Abajian JC. Spinal anesthesia for spine and lower extremity surgery in infants. J Pediatr Orthop. 1996;16: 259-263.

16. Abajian JC, Mellish RW, Browne AF, et al. Spinal anesthesia for surgery in the high-risk infant. Anesth Analg. 1984;63:359-362.

17. Puncuh F, Lampugnani E, Kokki H. Use of spinal anaesthesia in paediatric patients: a single centre experience with 1132 cases. Paediatr Anaesth. 2004;14:564-567. 
18. Bang-Vojdanovski B. Ten years of spinal anesthesia in infants and children for orthopedic surgery. Our clinical experience. Anesthetist. 1996;45:271-277.

19. Gupta A, Saha U. Spinal anesthesia in children: a review. J Anaesthesiol Clin Pharmacol. 2014;30:10-18.

20. Kokki H. Spinal blocks. Paediatr Anaesth. 2012;22:56-64.

21. López T, Sánchez FJ, Garzón JC, Muriel CT. Spinal anesthesia in pediatric patients. Minerva Anestesiol. 2012;78:78-87.

22. Rochette A, Troncin R, Raux O, et al. Clonidine added to bupivacaine in neonatal spinal anesthesia: a prospective comparison in 124 preterm and term infants. Paediatr Anaesth. 2005;15:1072-1077.
23. McCann ME, Withington DE, Arnup SJ, et al; GAS Consortium. Differences in blood pressure in infants after general anesthesia compared to awake regional anesthesia (GAS study - a prospective randomized trial). Anesth Analg. 2017;125:837-845.

24. Bailey A, Valley R, Bigler R. High spinal anesthesia in an infant. Anesthesiology. 1989;70(3):560.

25. Wright TH, Orr RJ, Haberkern CM, et al. Complications during spinal anesthesia in infants: high spinal blockade. Anesthesiology. 1990;73:1290-1292.

26. Tobias JD, Burd RS, Helikson MA. Apnea following spinal anaesthesia in two former pre-term infants. Can J Anaesth. 1998;45:985-989.
Local and Regional Anesthesia

\section{Publish your work in this journal}

Local and Regional Anesthesia is an international, peer-reviewed, open access journal publishing on the development, pharmacology, delivery and targeting and clinical use of local and regional anesthetics and analgesics. The journal is included in PubMed, and welcomes submitted papers covering original research, basic science, clinical studies,

\section{Dovepress}

reviews and evaluations, guidelines, expert opinion and commentary, case reports and extended reports. The manuscript management system is completely online and includes a very quick and fair peer-review system, which is all easy to use. Visit http://www.dovepress.com/ testimonials.php to read real quotes from published authors. 